\title{
tRNA-Derived Fragments Target the Ribosome and Function as Regulatory Non-Coding RNA in Haloferax volcanii
}

\author{
Jennifer Gebetsberger, ${ }^{1,2}$ Marek Zywicki, ${ }^{3,4}$ Andrea Künzi, ${ }^{1}$ and Norbert Polacek ${ }^{1,3}$ \\ ${ }^{1}$ Department of Chemistry and Biochemistry, University of Bern, Freiestraße 3, 3012 Bern, Switzerland \\ ${ }^{2}$ Graduate School for Cellular and Biomedical Sciences, University of Bern, 3012 Bern, Switzerland \\ ${ }^{3}$ Division of Genomics and RNomics, Innsbruck Biocenter, Innsbruck Medical University, Innrain 80/82, 6020 Innsbruck, Austria \\ ${ }^{4}$ Laboratory of Computational Genomics, Institute of Molecular Biology and Biotechnology, Adam Mickiewicz University, \\ 61-712 Poznan, Poland
}

Correspondence should be addressed to Norbert Polacek, norbert.polacek@dcb.unibe.ch

Received 14 September 2012; Revised 16 November 2012; Accepted 28 November 2012

Academic Editor: Anita Marchfelder

Copyright (C) 2012 Jennifer Gebetsberger et al. This is an open access article distributed under the Creative Commons Attribution License, which permits unrestricted use, distribution, and reproduction in any medium, provided the original work is properly cited.

\begin{abstract}
Nonprotein coding RNA (ncRNA) molecules have been recognized recently as major contributors to regulatory networks in controlling gene expression in a highly efficient manner. These RNAs either originate from their individual transcription units or are processing products from longer precursor RNAs. For example, tRNA-derived fragments (tRFs) have been identified in all domains of life and represent a growing, yet functionally poorly understood, class of ncRNA candidates. Here we present evidence that tRFs from the halophilic archaeon Haloferax volcanii directly bind to ribosomes. In the presented genomic screen of the ribosome-associated RNome, a 26-residue-long fragment originating from the $5^{\prime}$ part of valine tRNA was by far the most abundant tRF. The Val-tRF is processed in a stress-dependent manner and was found to primarily target the small ribosomal subunit in vitro and in vivo. As a consequence of ribosome binding, Val-tRF reduces protein synthesis by interfering with peptidyl transferase activity. Therefore this tRF functions as ribosome-bound small ncRNA capable of regulating gene expression in $H$. volcanii under environmental stress conditions probably by fine tuning the rate of protein production.
\end{abstract}

\section{Introduction}

Recent research revealed small nonprotein coding RNAs (ncRNAs) as pivotal players in regulatory networks shaping cellular life in all three phylogenetic domains (reviewed in [1]). Regulatory functions of ncRNAs are diverse ranging from chromosome biology, to epigenetics, transcription, and translation regulation [2]. This variety of ncRNA functions is mirrored by their complex genomics and biogenesis. Recent data suggest that a single ncRNA transcript can adopt different structures and thus perform distinct functional roles depending on different posttranscriptional processing events. Four years ago it could be shown that a functional small nucleolar RNA, which was initially processed from an mRNA intron, could function as a microRNA after further processing took place [3]. Many other reports followed expanding the list of ncRNA species that are target of further downstream processing into novel regulatory entities [4-7] thus it appears that we have just started to disentangle the hidden layers of the transcriptome.

One recent example of ncRNA processing presents the emerging group of RNA fragments derived from mature tRNAs or precursor tRNAs [8]. These tRNA-derived fragments (tRFs) have long been regarded as random byproducts of tRNA biogenesis or degradation, but are now recognized as emerging players in tRNA biology. tRFs have been uncovered by deep sequencing projects in all three domains of life (reviewed in [8]). These tRFs have been shown to be produced under specific growth conditions and differ in size and sequence, thus indicating physiological relevance. Their biological functions, however, remained largely enigmatic. Several reports show a possible involvement of tRFs in cell proliferation [9], in the siRNA and microRNA pathway [8, 10-12] and in protein biosynthesis [13-16]. In those studies presenting functional experiments, it appears that tRFs are capable of globally downregulating protein synthesis. This 
tRF-induced inhibition of translation is not however due to a reduced pool of genuine tRNA molecules. A recent study by Ivanov et al. suggests that specific $5^{\prime}$ tRFs inhibit translation initiation in oxidatively stressed human cell lines by recruiting eIF4E/G/A from capped mRNAs or eIF4G/A from uncapped mRNAs [13]. If translation initiation is the sole target for tRFs in regulating protein synthesis or whether other phases of the ribosomal elongation cycle might be targeted by this ncRNA class remains to be seen.

In this study, we present evidence that in the archaeal model species Haloferax volcanii tRFs are processed in a stress-dependent manner and are capable of directly binding to the ribosome. Our deep-sequencing analysis of the ribosome-associated small RNome revealed four classes of tRFs. We present experimental evidence that one of these tRFs primarily target the small ribosomal subunit and demonstrate its inhibitory role in peptide bond formation and during in vitro translation. This is the first report of a tRF directly binding to the key enzyme of protein synthesis and therefore tRFs in H. volcanii represent ribosome-targeted regulatory ncRNA species.

\section{Material and Methods}

2.1. Strain and Growth Conditions. Haloferax volcanii strain $\mathrm{H} 26$ was grown aerobically at $42^{\circ} \mathrm{C}$ in complex medium $\left(2.9 \mathrm{M} \mathrm{NaCl}, 150 \mathrm{mM} \mathrm{MgSO}_{4} \times 7 \mathrm{H}_{2} \mathrm{O}, 60 \mathrm{mM} \mathrm{KCl}\right.$, $4 \mathrm{mM} \mathrm{CaCl}_{2}, 50 \mathrm{mM}$ Tris- $\mathrm{HCl}(\mathrm{pH} 7.2), 0.45 \%$ (w/v) tryptone, $0.275 \%(\mathrm{w} / \mathrm{v})$ yeast extract). Cells were subjected to different temporary and permanent stress conditions as described [17]. In the case of temporary stress $H$. volcanii precultures were grown under standard conditions to the mid exponential phase $\left(\mathrm{OD}_{600}=0.5 \pm 0.1\right)$ before environmental stress was applied for one respectively four hours. These stress conditions included cold shock at $30^{\circ} \mathrm{C}$ and heat shock at $60^{\circ} \mathrm{C}$. For $\mathrm{pH}$ stress the cultures were either supplemented with $0.1 \mathrm{M}$ Tris- $\mathrm{HCl}(\mathrm{pH}$ 8.5-9.5) resulting in an elevated $\mathrm{pH}$ or with $12 \mathrm{mM} \mathrm{Na}(\mathrm{O}) \mathrm{Ac}$ for low $\mathrm{pH}$ conditions. Oxidative stress was induced by the addition of $\mathrm{H}_{2} \mathrm{O}_{2}$ to a final concentration of $0.78 \%$ (low oxidative stress) and $1.43 \%$ (high oxidative stress). For the ultraviolet (UV) stress the cells were irradiated with a UV dose of $120 \mathrm{~J} / \mathrm{m}^{2}$ for 30 seconds. For osmotic stress, the cells were collected by centrifugation and resuspended in the appropriate salt stress medium $(0.9 \mathrm{M} \mathrm{NaCl}, 1.5 \mathrm{M} \mathrm{NaCl}$, $300 \mathrm{mM} \mathrm{MgSO}_{4} \times 7 \mathrm{H}_{2} \mathrm{O}$ ). For setting a permanent stress the cells were challenged from the inoculation until an $\mathrm{OD}_{600}=$ $1.0 \pm 0.2$ was reached. These stress conditions included UV irradiation, alkaline stress $(\mathrm{pH} 8.5)$, and growth under different salt concentrations ( $1.5 \mathrm{M} \mathrm{NaCl}, 300 \mathrm{mM} \mathrm{MgSO}_{4} \times$ $\left.7 \mathrm{H}_{2} \mathrm{O}\right)$ as described above. The growth was monitored at selected time points by measuring the absorbance at $\mathrm{OD}_{600}$.

2.2. cDNA Library Generation. For the cDNA library preparation equal volumes of unstressed and stressed $H$. volcanii cells (for different stress conditions see above) were pooled and ribosomes were isolated basically as described [18] using buffer $\mathrm{P}$ [19] (3.4 M KCl, $100 \mathrm{mM} \mathrm{Mg}(\mathrm{OAc})_{2}, 6 \mathrm{mM}$ 2-mercaptoethanol, $10 \mathrm{mM}$ Tris- $\mathrm{HCl} \mathrm{pH}$ 7.6). Ribosomeassociated RNA was size-selected (ranging from 20-500 nucleotides), extracted, precipitated with ethanol, and used for cDNA library construction as described [7]. The cDNA library was deepsequenced (max. read lengths $76 \mathrm{bp}$ ) using the illumina platform (FASTERIS SA).

2.3. Data Analysis of the Deep Sequencing Results. The analysis of the sequence reads was performed using the APART pipeline (automated pipeline for annotation of RNA transcripts) [7]. In short, the sequences were cleaned by removal of the adaptor sequences and subsequently mapped to the $H$. volcanii genome where overlapping reads were assembled into contigs. From all 73.5 Mio raw reads originally obtained only reads with a minimal length of 18 nucleotides that contained both the $5^{\prime}$ and $3^{\prime}$ adaptors were further analyzed. At the genome mapping stage only a single mismatch was allowed.

2.4. Polysome Gradients. H. volcanii cells grown under normal conditions and permanent $\mathrm{pH} 8.5$ stress condition (as described above) were collected by centrifugation, frozen in liquid nitrogen, and grounded three times in a precooled mortar. The resulting powder was resuspended in buffer A $\left(3 \mathrm{M} \mathrm{KCl}, 150 \mathrm{mM} \mathrm{MgCl}_{2}, 6 \mathrm{mM}\right.$ 2-mercaptoethanol, $10 \mathrm{mM}$ Tris- $\mathrm{HCl} \mathrm{pH}$ 7.6, $0.5 \mathrm{mM}$ DTT, $26 \mu \mathrm{M}$ tetracycline hydrochloride) and the cell debris was removed by centrifugation $(30,000 \times \mathrm{g}, 15 \mathrm{~min})$. The supernatant was treated with RNase-free DNase (10 min on ice) and subjected to a second centrifugation $(30,000 \times \mathrm{g}, 15 \mathrm{~min})$. The supernatant, referred to as $\mathrm{S} 30$, was layered onto a linear sucrose gradient containing 10-40\% (w/v) sucrose prepared in buffer A and centrifuged in a Beckman SW-41 rotor $(4 \mathrm{~h}, 35,000 \mathrm{rpm}$, $4^{\circ} \mathrm{C}$ ). Fractions containing polysomes, 50S, and $30 \mathrm{~S}$ subunits were collected while monitoring the absorbance at $260 \mathrm{~nm}$. For downstream northern blot analyses, the fractions were dialyzed two times against pure water $\left(2 \mathrm{~h}, 4^{\circ} \mathrm{C}\right)$ and precipitated with ethanol before separation on $8 \%$ polyacrylamide gels.

2.5. Northern Blot Analysis. Total RNA from H. volcanii grown under selected conditions was isolated using TRI Reagent (Sigma Aldrich) according to the manufacturer's instruction. Size-selected ribosome-associated RNA was prepared by isolating RNA from crude ribosomes by phenol/ chloroform extraction followed by size fractionation employing denaturating 8\% PAGE. RNAs in the size range between 20 and $500 \mathrm{nt}$ were excised from the gel, passively eluted into $0.3 \mathrm{M} \mathrm{NaOAc}$ at $4^{\circ} \mathrm{C}$, and ethanol precipitated. Ribosomal particles (polysomes, 50S, or 30S subunits) were isolated using sucrose gradient centrifugation (as described above), followed by RNA extraction using phenol/ chloroform and ethanol precipitation. For northern blot analysis the RNA $(2.5-10 \mu \mathrm{g})$ was separated on $8 \%$ denaturating polyacrylamide gel ( $7 \mathrm{M}$ Urea, $1 \times \mathrm{TBE}$ buffer), transferred onto nylon membranes (Amersham Hybond$\mathrm{N}^{+}$, GE Healthcare) using a semidry blotting apparatus (V20-SDB, Scie-Plas). After immobilizing of RNA using 
a UV cross-linker (BLX-254, Vilber Lourmat) the nylon membranes were prehybridized for 30 minutes in hybridization buffer (1 M sodium phosphate buffer $\mathrm{pH}$ 6.2, 7\% SDS). DNA oligonucleotides complementary to the RNA of interest were end-labeled with $\left[\gamma^{32} \mathrm{P}\right]$-ATP and T4 polynucleotide kinase. Hybridization was carried out in $1 \mathrm{M}$ sodium phosphate buffer ( $\mathrm{pH} 6.2,7 \%$ SDS) over night at $52^{\circ} \mathrm{C}$ in a hybridization oven. Blots were washed once (room temperature) with washing buffer I $(30 \mathrm{mM}$ sodium citrate $\mathrm{pH} 7.0,0.3 \mathrm{M} \mathrm{NaCl}, 0.1 \% \mathrm{SDS}$ ) and once (room temperature or $\left.52^{\circ} \mathrm{C}\right)$ with washing buffer II $(1.5 \mathrm{mM}$ sodium citrate $\mathrm{pH} 7.0,15 \mathrm{mM} \mathrm{NaCl}, 0.1 \%$ SDS) for 10 minutes each. Membranes were exposed to phosphor imaging screens. The signals were monitored with a phosphor imager (FLA-3000; Fuji Photo Film) and analyzed quantitatively with the densitometric program Aida Image Analyzer. Following DNA oligonucleotides were used for northern blotting targeting tRFs (depicted in $5^{\prime}-3^{\prime}$ direction): $\operatorname{Val}(\mathrm{GAC})$ TCATAACCAGACTAGACCACCAACCC, Cys(GCA) CCGAACTCTGCCACCTTGGC Ser(GCT) CCAGGCTTGGCTACCGCAAC, Leu(CAG) CCAGACTTGGCTATCCCTGC, Arg(GCG) ATAGTCCACTACCCTATCAGGAC, Ala(GGC) ATCTACCCCTGATCTACGAGCCC, Leu(GAG) CCTGGCTTGGCTACCCACGC, Val(CAC) TCATAACCTGGCTAGACCACCAACCC, Gly(CCC) CTACCACTGGACCATCGGCGC, Asp(GTC) TCGTATGATGGGCCACTACACCACCCGGGC, Leu(CAA) ATTTGAACCCACGGACCCCTACGGGAGCGGAT, Ser(GGA) CCTTACCGCTCGGCCATCCTGGC, Val(GAC) TGGGTTGGGGCAGATTTGAA.

2.6. In Vitro Binding Studies. Binding studies of Val-tRF were performed using a dot blot-filtering device. For the experiments $10 \mathrm{pmol}$ of $H$. volcanii ribosomal particles (70S, 50S, 30S) were incubated with 4 pmol $5^{\prime}\left[{ }^{32} \mathrm{P}\right]$-endlabeled synthetic RNA $(1.750 \mathrm{cpm} / \mathrm{pmol})$ (Val-tRF $5^{\prime}$ GGGUUGGUGGUCUAGUCUGGUUAUGA-3', Ile-tRF 5'. GGGCCAAUAGCUCAGUCAGGUUGAGC-3') in $25 \mu \mathrm{L}$ binding buffer (f.c. $20 \mathrm{mMHepes} / \mathrm{KOH}$ pH 7.6, $6 \mathrm{mM}$ $\mathrm{MgAc}_{2}, 150 \mathrm{mM} \mathrm{NH}_{4} \mathrm{Cl}, 4 \mathrm{mM}$ 2-mercaptoethanol, $2 \mathrm{mM}$ spermidine, $50 \mu \mathrm{M}$ spermine). As positive control E. coli $70 \mathrm{~S}$ were incubated with $50 \mu \mathrm{g}$ polyU-mRNA and $5^{\prime}\left[{ }^{32} \mathrm{P}\right]-$ end-labeled deacylated tRNA ${ }^{\text {Phe }}(7,000 \mathrm{cpm})$. After $30 \mathrm{~min}$ incubation on ice the reactions were filtered through a nitrocellulose membrane $(0.45 \mu \mathrm{m}$ diameter $)$ using a vacuum device, followed by two washing steps with cold binding buffer. The membrane was quantified as described above.

2.7. In Vitro Translation. For in vitro translation an S30 extract from $H$. volcanii was prepared as described above and stored in aliquots at $-80^{\circ} \mathrm{C}$. For 16 translation reactions the following components were added to $150 \mu \mathrm{L} \mathrm{S30}$ extract: $25 \mu \mathrm{L}$ of $10 \times$ translation cocktail $(100 \mathrm{mM}$ HEPES$\mathrm{KOH}$ pH 7.4, $15 \mathrm{mM} \mathrm{Mg}(\mathrm{OAc})_{2}, 750 \mathrm{mM}$ KOAc, 4 mM GTP, $10 \mathrm{mM}$ ATP, $500 \mu \mathrm{M}$ of all amino acids except methionine and cysteine), $2.5 \mu \mathrm{L}$ creatine phosphokinase $(10 \mathrm{mg} / \mathrm{mL}$, Roche), $5 \mu \mathrm{L}$ creatine phosphate $(0.6 \mathrm{M}$, Roche), $2.5 \mu \mathrm{L}$ $\mathrm{Mg}(\mathrm{OAc})_{2}(100 \mathrm{mM})$, and $5 \mu \mathrm{L}$ bulk brewer's yeast tRNA $\left(10 \mathrm{mg} / \mathrm{mL}\right.$, Roche). Before the addition of $10 \mu \mathrm{L}\left[{ }^{35} \mathrm{~S}\right]$ cysteine/methionine $(10 \mu \mathrm{Ci} / \mu \mathrm{L})$, a preincubation step for $10 \mathrm{~min}$ at $23^{\circ} \mathrm{C}$ was performed. $12 \mu \mathrm{L}$ of translation mixture were used per reaction to which 50 pmol tRFs or $\mathrm{H}_{2} \mathrm{O}$ was added to a final volume of $15 \mu \mathrm{L}$. In vitro translation was performed at $23^{\circ} \mathrm{C}$ for $30 \mathrm{~min}$ and was stopped by the addition of $1 \mathrm{~mL} 20 \% \mathrm{TCA}$ and incubation at $95^{\circ} \mathrm{C}$ for 15 minutes. The TCA-precipitated proteins were filtered through glassfiber filter and quantified by liquid scintillation counting. The background counts observed in analogous samples but in the absence of S30 extract (in average 30-fold lower than in complete in vitro translation reactions containing S30) was always subtracted.

2.8. Peptidyl Transferase Assay. Peptide bond formation activity was tested using a modified peptidyl transferase assay under fragment reaction conditions [20] with $\mathrm{N}$-acetyl- $\left[{ }^{3} \mathrm{H}\right]$ Phe-tRNA $(15,000 \mathrm{cpm} / \mathrm{pmol})$ [21] as the donor substrate and puromycin as acceptor. The assay was performed in $25 \mu \mathrm{L}$ of high salt buffer $(2 \mathrm{M} \mathrm{KCl}$, $30 \mathrm{mM}$ Tris- $\mathrm{HCl} \mathrm{pH}$ 7.6, $0.4 \mathrm{M} \mathrm{NH}_{4} \mathrm{Cl}, 60 \mathrm{mM} \mathrm{Mg}(\mathrm{OAc})_{2}$, $7 \mathrm{mM}$ 2-mercaptoethanol, $2 \mu \mathrm{M}$ spermidine, $0.05 \mathrm{mM}$ spermine) containing $10 \mathrm{pmol}$ of $H$. volcanii $70 \mathrm{~S}$ ribosomes, respectively, $50 \mathrm{~S}$ subunits, $0.8 \mathrm{pmol} \mathrm{N}$-acetyl- $\left[{ }^{3} \mathrm{H}\right] \mathrm{Phe}-$ tRNA, puromycin (f.c. $1 \mathrm{mM}$ ) and, as indicated, $100 \mathrm{pmol}$ of the RNA of interest (Val-tRF, Ile-tRF, or scr 5' GUUGUUCGCUGUGAGGUGGUGAAUUG- $3^{\prime}$ ). The transpeptidation reaction was initiated by the addition of $12.5 \mu \mathrm{L}$ cold methanol (f.c. $33 \%$ ) and incubated for $3.5 \mathrm{~h}$ on ice. In order to test for potential P-site competition between $\mathrm{N}$ acetyl- $\left[{ }^{3} \mathrm{H}\right]$ Phe-tRNA and Val-tRF, 0.8 pmol of the peptidyltRNA analog was preincubated in the presence of $100 \mathrm{pmol}$ Val-tRF and 33\% methanol for 20 minutes on ice before the reaction was initiated by the addition of puromycin. In a control experiment, the Val-tRF was added simultaneously with the A-site substrate puromycin to ribosomal complexes that carried already a prebound $\mathrm{N}$-acetyl- $\left[{ }^{3} \mathrm{H}\right]$ Phe-tRNA $(0.8 \mathrm{pmol})$. In all cases the reaction was terminated by the addition of $5 \mu \mathrm{L} 10 \mathrm{M} \mathrm{KOH}$ followed by an incubation for $15 \mathrm{~min}$ at $37^{\circ} \mathrm{C}$. After the addition of $100 \mu \mathrm{L} 1 \mathrm{M} \mathrm{KH}_{2} \mathrm{PO}_{4}$ the reaction product ( $\mathrm{N}$-acetyl- $\left[{ }^{3} \mathrm{H}\right]$ Phe-puromycin) was extracted into $1 \mathrm{~mL}$ cold ethyl acetate by vortexing for $1 \mathrm{~min}$. $800 \mu \mathrm{L}$ of the upper organic phase were measured using a liquid scintillation counter.

\section{Results}

3.1. tRNA-Derived Fragments Are Abundant in the RNA Interactome of $H$. volcanii Ribosomes. In the course of studying the ncRNA interactome of the archaeal ribosome, we have constructed a specialized cDNA library from small RNAs (sized 20-500 nt) that copurifies with ribosomes of $H$. volcanii under different environmental stress conditions. In order to select for functional ncRNAs putatively involved in translation regulation we have set temporary stress (UV, cold shock, heat shock, low $\mathrm{pH}$, high $\mathrm{pH}$, oxidative stress, low $\mathrm{NaCl}$, high $\mathrm{MgSO}_{4}$ ) for one, respectively four hours, as well as permanent stress ( $\mathrm{UV}$, high $\mathrm{pH}$, low $\mathrm{NaCl}$, high $\mathrm{MgSO}_{4}$ ). For the library construction small RNAs that copurified with 


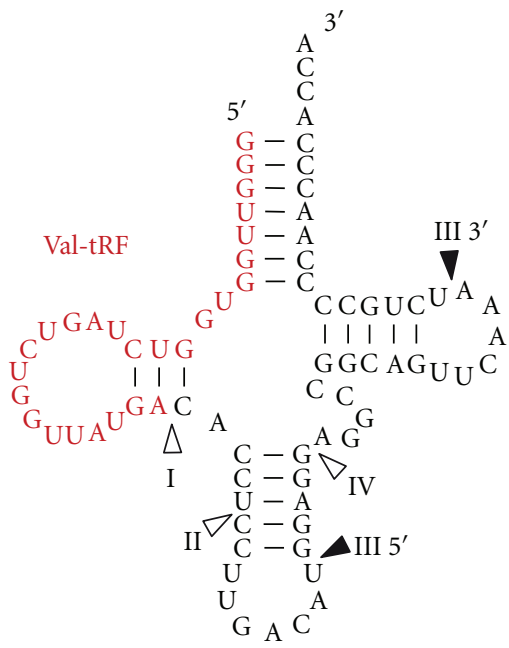

(a)

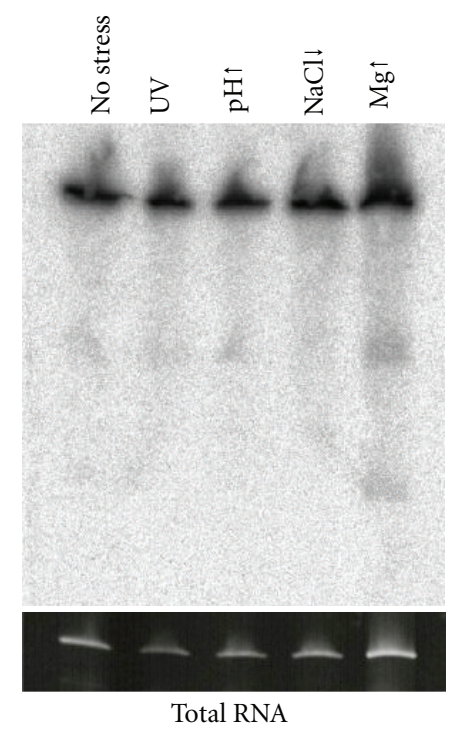

(b)

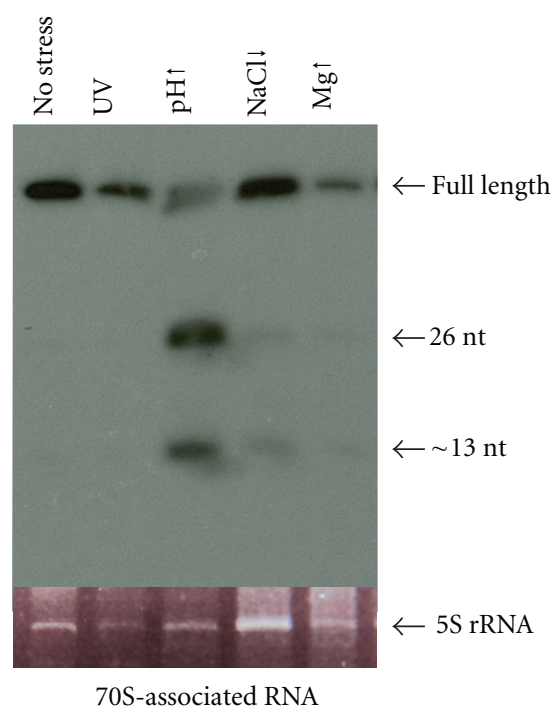

(c)

Figure 1: Processing and expression of Val-tRF. (a) Secondary structure of H. volcanii Val-tRNA with the Val-tRF depicted in red. Arrowheads indicate the processing positions for the four different observed tRF classes (I-IV). Open arrowheads on the Val-tRNA structure indicate the $3^{\prime}$ ends of the tRFs for class I, as well as the analogous positions for the other tRF classes II, and IV. tRFs from classes I, II, and IV are all processed from the $5^{\prime}$ end of mature tRNAs. Filled arrowheads mark the $5^{\prime}$ and $3^{\prime}$ ends of tRFs derived from class III. Northern blot analyses for Val-tRF were performed using (b) total RNA or (c) ribosome-associated RNA. RNA was isolated from unstressed H. volcanii cells (no stress), or cells grown under different permanent environmental stress conditions (ultraviolet stress (UV), high $\mathrm{pH}$ ( $\mathrm{pH} \uparrow$ ), $0.9 \mathrm{M} \mathrm{NaCl}$ $\left.(\mathrm{NaCl} \downarrow), 300 \mathrm{mM} \mathrm{MgSO}_{4}(\mathrm{Mg} \uparrow)\right)$. Arrows indicate the full-length tRNA and the detected processing products. In all panels 5S rRNA served as internal loading control.

H. volcanii ribosomes isolated from stressed and unstressed cultures were reverse transcribed into cDNA. The subsequent deep sequencing yielded 73.5 million raw reads which were analyzed using the APART pipeline [7], ending up with 19.2 million reads for downstream analysis which were grouped into 6.250 putative ribosome-associated ncRNA candidates (our unpublished data). Among other potential novel ncRNAs we significantly observed the emersed presence of tRNA-derived fragments (tRFs) originating from 14 different tRNAs (Table 1). Based on their sizes and processing ends we have categorized them into four different classes of which class I, with a size distribution of 20-26 nt and the $3^{\prime}$-end located in the D-stem, is the most prominent one (1.3 million reads). Interestingly, tRFs of all classes (with the exception of class IV) are processed from the $5^{\prime}$ end of the mature tRNA (for a schematic representation see Figure 1(a)). No reads encompassing $3^{\prime}$-derived tRFs were obtained in our library. The presence of tRFs in a library constructed from the ribosome-bound RNome suggests that $5^{\prime}$ tRFs (but not $3^{\prime}$ tRFs) are capable of interacting with the translation machinery. Bioinformatic analyses failed to detect any correlations between the processed tRNAs and the codon usage statistics in $H$. volcanii.

3.2. Valine tRF Is Highly Abundant and Associates with the Ribosome. With more than 1.1 million reads $(85 \%$ of all detected tRF reads) a 26-residue-long fragment deriving from valine tRNA showed unexpected high abundancy
(Table 1). Whereas in H. volcanii four genes give rise to ValtRNAs, our observed tRF originates from two paralogous tRNA genes decoding for valine (GAC), positioned adjacent in the genome. To confirm the presence of this tRF and to investigate its potential association with ribosomes, northern blot analyses were performed. While only very faint bands for Val-tRNA processing products were seen when total RNA was used for northern blotting (Figure 1(b)), clear bands of the expected size of about 26 nucleotides were detected in blots using ribosome-associated RNAs (Figure 1(c)). Obviously the Val-tRF is enriched in the latter RNA preparation thus supporting our assumption of Val-tRF being a ribosomebound RNA species. Even extended incubation times with a northern blot probe targeting the $3^{\prime}$ part of Val-tRNA failed to identify any processing product (data not shown). Thus only the $5^{\prime}$ tRF has the potential to bind to ribosomes. From Figure 1(c), it is also obvious that Val-tRF is processed differently in response to diverse stress conditions. At elevated $\mathrm{pH}$ this tRF is most abundant.

3.3. tRFs Are Differentially Expressed under Stress. In order to clarify whether tRFs from all four classes found in our library are part of the ribosome-derived RNome, northern blot analyses were performed (Figure 2). It turned out that indeed signals for almost all tested tRFs were observed; however, the processing pattern as well as the abundance was distinct. While the class I tRF derived from Ala-tRNA showed a very similar processing pattern to Val-tRF at elevated $\mathrm{pH}$ as 


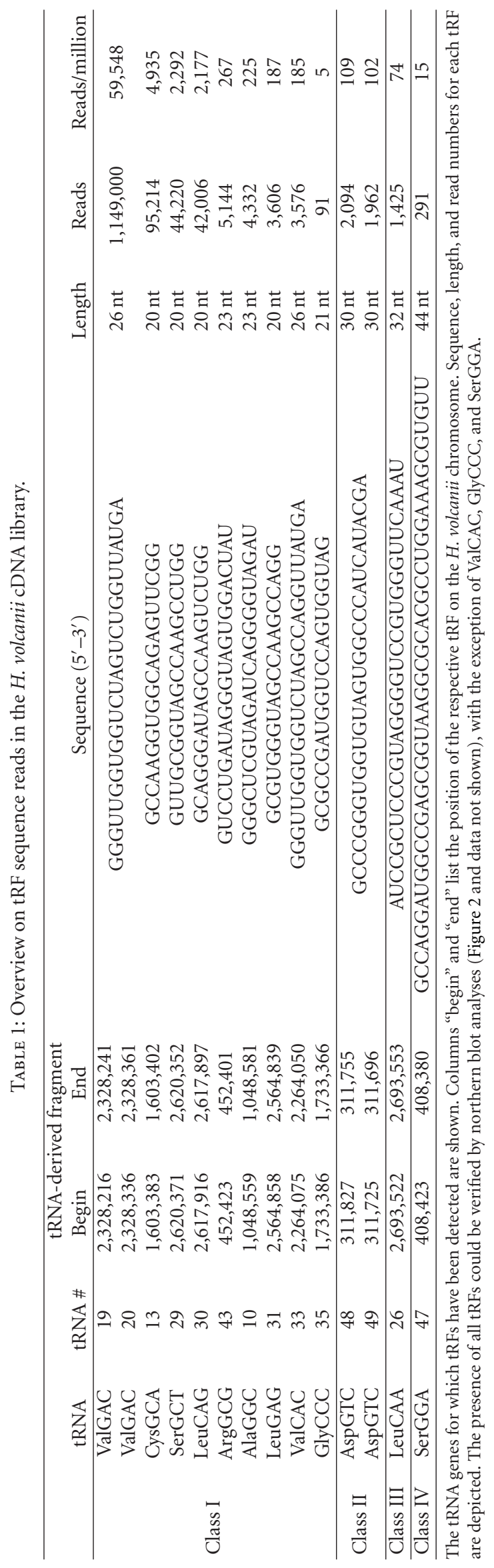



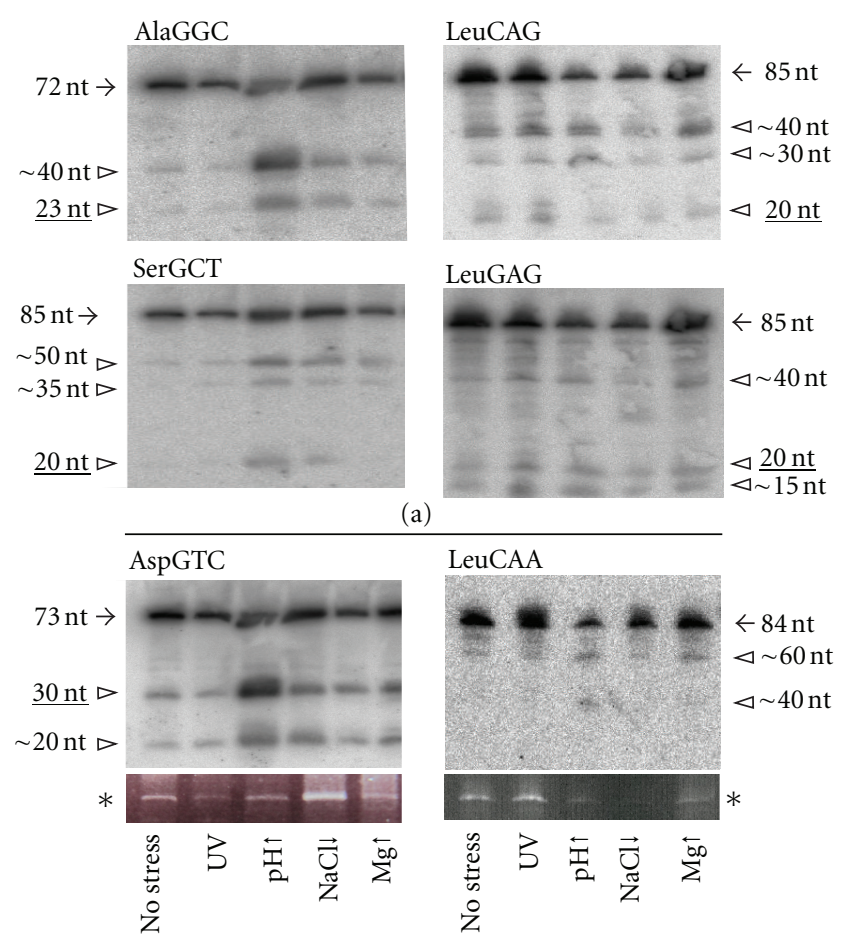

(b)

(c)

FIgURE 2: tRFs are present in the ribosome-associated RNome. Northern blot analyses of tRFs confirm the presence of class I (a), class II (b), and class III (c) tRFs in the ribosome-associated RNA fraction. The full-length tRNA signals are depicted by black arrows and tRFs by open arrow heads. Approximate lengths of the fragments, as deduced from RNA markers, are indicated. tRFs corresponding to the sequence reads of the cDNA library (Table 1) are underlined. RNA was isolated from unstressed $H$. volcanii cells (no stress), or cells grown under different permanent environmental stress conditions (ultraviolet stress (UV), high $\mathrm{pH}$ $\left(\mathrm{pH} \uparrow\right.$ ), $0.9 \mathrm{M} \mathrm{NaCl}(\mathrm{NaCl} \downarrow), 300 \mathrm{mM} \mathrm{MgSO}_{4}(\mathrm{Mg} \uparrow)$ ). The $5 \mathrm{~S}$ rRNA (asterisk) of ethidium bromide stained gels served as loading controls.

the condition of most significant tRF processing, the class I tRFs from Leu-tRNA were markedly different. Nevertheless, the fact that these tRFs could be readily detected via northern blot analyses on ribosome-derived RNA suggests that the tRFs identified in our genomic screen are capable of interacting with the ribosome in $H$. volcanii.

\subsection{Valine tRF Primarily Binds to the Small Ribosomal} Subunit. To more precisely investigate the tRF interaction with the ribosome, polysome gradient analyses and in vitro binding studies were performed. $H$. volcanii cell lysates were passed through a linear sucrose gradient in order to separate the polysomal fraction from nontranslating 70 S ribosomes and ribosomal subunits. RNA isolated from these fractions was used for northern blot analysis employing a radiolabelled antisense probe targeting Val-tRF (Figures 3(a) and 3(b)). The data revealed that Val-tRF was primarily comigrating with the $30 \mathrm{~S}$ subunit fraction (Figure 3(b); unstressed and $\mathrm{pH} 8.5$ stress) in density gradients. Only after high $\mathrm{pH}$ stress, Val-tRF signals were also obtained in the polysomal fraction
(Figure 3(b)). This is evidence for a putative functional role of Val-tRF during stress response. To more directly investigate ribosome-association, radiolabelled synthetic Val-tRF was bound to purified $H$. volcanii ribosomes or subunits in a filter binding setup. The binding data show that Val-tRF can indeed associate with $70 \mathrm{~S}$ ribosomes and $30 \mathrm{~S}$ subunits, while 50S particles were less efficiently targeted (Figure 3(c)). Obviously, no additional cellular proteins are required for ribosome binding. As a negative control, an analogous tRF deriving from a comparable region of isoleucine tRNA, a fragment that was not represented in our deep-sequence library, was used. This isoleucine tRNA-derived fragment (Ile-tRF) was unable to bind to the ribosome in a comparable manner (Figure 3) thus highlighting binding specificity of the Val-tRF.

\subsection{Valine tRF Inhibits In Vitro Translation by Interfering} with Peptide Bond Formation. The observation that Val-tRF strongly binds to ribosomes led to the speculation of a potential effect as regulatory ncRNA during protein biosynthesis. To clarify this we set up an in vitro translation system for $H$. volcanii and quantified the amount of synthesized proteins in the presence or absence of Val-tRF. Repeatedly, ValtRF decreased translation efficiency of the total $H$. volcanii mRNA population by about $45 \%$ (Figure 4(a)). Importantly a 26-mer composed of a scrambled sequence of the ValtRF did not show any inhibition of protein synthesis, thus hinting at a sequence-specific effect. This effect of Val-tRF on in vitro translation also helps explaining the observed severe growth defect, when $H$. volcanii was grown in alkaline media (Figure 4(b)). Under these environmental conditions Val-tRF is most strongly associated with ribosomes in vivo (Figure 1(b)).

Protein synthesis is a multistep process involving the orchestrated action of several protein cofactors, including initiation, elongation, and termination factors. To reveal whether the ribosome itself or any of the translation factors needed for protein synthesis are inhibited by Val-tRF, we performed a peptidyl transfer assay utilizing purified $H$. volcanii ribosomes. The transpeptidation assay was performed using $\mathrm{N}$-acetyl- $\left[{ }^{3} \mathrm{H}\right]$ Phe-tRNA as donor and the antibiotic puromycin as acceptor substrate. In this experimental setup, Val-tRF inhibited the extent of peptide bond formation by about $60 \%$, while the scrambled sequence of the ValtRF had hardly any inhibitory effect (Figure 5). As second specificity control served the Ile-tRF previously used in the binding studies (see Figure 3(c)). As shown before this RNA was unable to efficiently bind to $H$. volcanii ribosomes (Figure 3(c)) and had also no inhibitory effects on the peptidyl transferase reaction (Figure 5).

To functionally define the site of action of the ValtRF, the puromycin reaction was repeated under identical reaction conditions, but in the presence of $50 \mathrm{~S}$ subunits alone. In this experimental setup, Val-tRF did not inhibit transpeptidation, thus confirming that the prime binding target for Val-tRF is the small ribosomal subunit. A possible mechanism for inhibiting the puromycin reaction is that the Val-tRF competes with the P-site substrate $\mathrm{N}$-acetyl$\left[{ }^{3} \mathrm{H}\right]$ Phe-tRNA for ribosome binding. This could occur if 


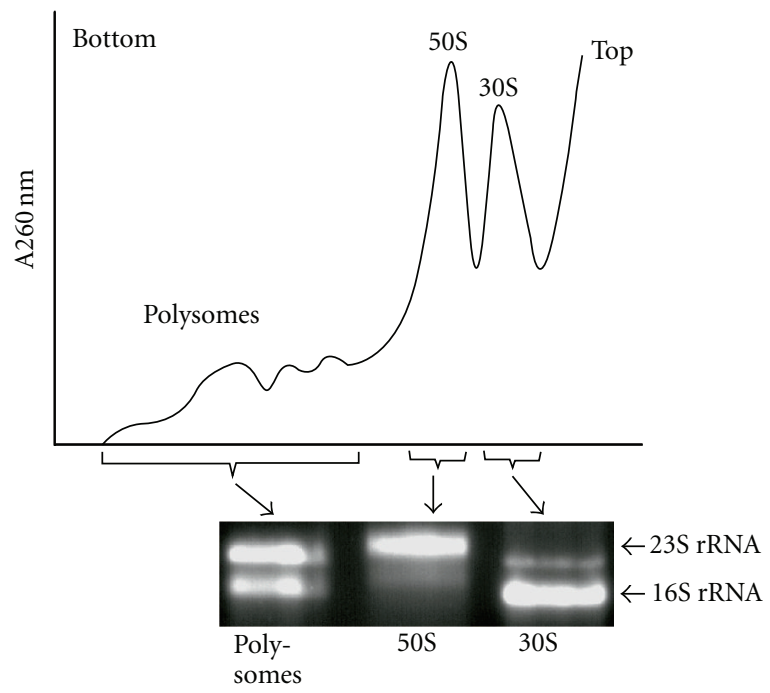

(a)

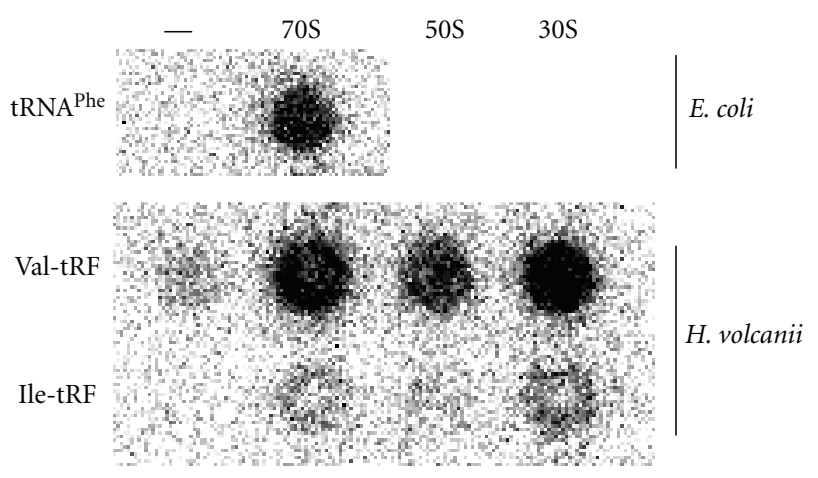

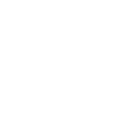

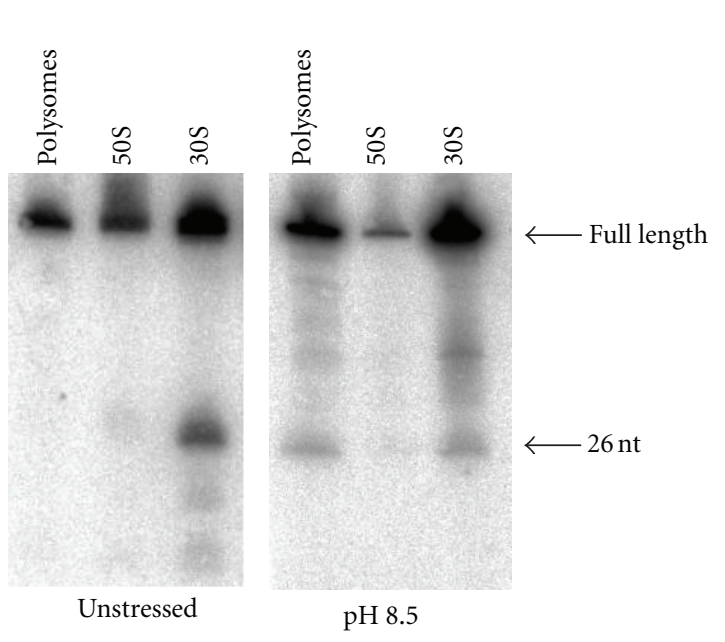

(b)

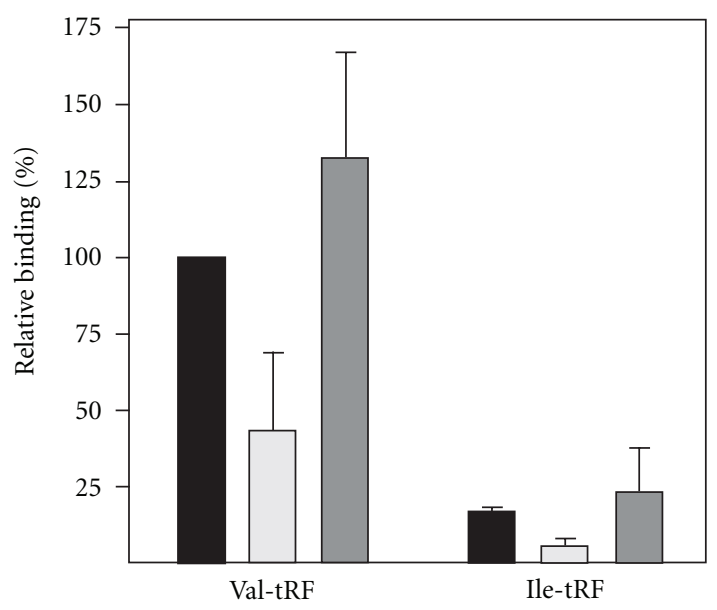

$70 \mathrm{~S}$
$\square \quad 50 \mathrm{~S}$
$\square 30 \mathrm{~S}$

(c)

FIGURE 3: Val-tRF associates with ribosomes in vitro and in vivo. (a) A representative polysome gradient of $H$. volcanii. Fractions containing polysomes, 50S, or $30 \mathrm{~S}$ subunits were collected and used for northern blot analyses. The identity of the individual fractions was confirmed by agarose gel electrophoresis. (b) The presence of the Val-tRF in the different gradient fractions was investigated by northern blot analysis using RNA from unstressed cells or from cultures incubated at high $\mathrm{pH}(\mathrm{pH}$ 8.5). Arrows indicate the full-length Val-tRNA and the 26 nt long fragment detected in the cDNA library. (c) In vitro filter binding studies of radiolabelled synthetic Val-tRF on ribosomal particles (70S, $50 \mathrm{~S}, 30 \mathrm{~S}$ ) from $H$. volcanii (left panel). As a positive control, binding of tRNA ${ }^{\text {Phe }}$ to E. coli $70 \mathrm{~S}$ was monitored. To confirm specific binding of Val-tRF an equally long fragment of isoleucine tRNA (Ile-tRF), an RNA sequence not found in our cDNA screen, served as negative control. (Right panel) Quantification of relative binding whereas association of Val-tRF to 70S was normalized to 100\%. Signals measured in the absence of any ribosomal particles (-) were subtracted from all experimental points. Error bars show the mean and standard deviation of at least four independent experiments.

the Val-tRF would be able to refold into a hairpin structure resembling an anticodon stem-loop. Even though secondary structure analyses by $\mathrm{M}$-fold did not indicate any stable stem-loop structure of Val-tRF (data not shown), we decided to experimentally test the P-site competition hypothesis. Therefore we slightly modified the peptidyl transferase assay namely; we incubated N-acetyl- $\left[{ }^{3} \mathrm{H}\right] \mathrm{Phe}$-tRNA simultaneously with a 125-fold excess of Val-tRF for 20 minutes before the reaction was initiated by the addition of puromycin. Under these conditions significant inhibition of transpeptidation was observed (Figure 5(b)), thus potentially P-site competition occurred. If this Val-tRF triggered inhibition 


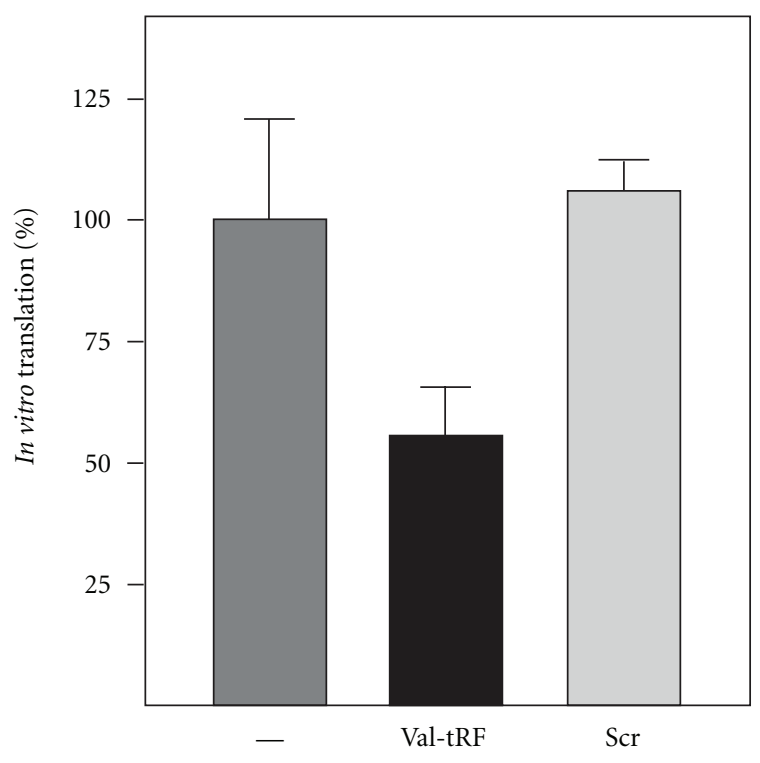

(a)

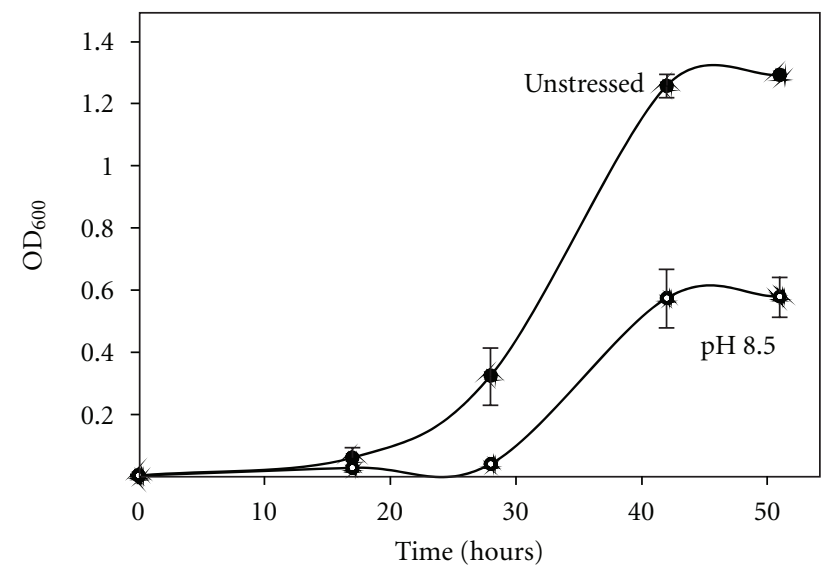

(b)

FIGURE 4: Effects of Val-tRF or elevated $\mathrm{pH}$ on protein synthesis and cell growth. (a) Val-tRF inhibits $H$. volcanii in vitro translation. The relative amount of radiolabeled proteins in the absence (-) or in the presence of $3.3 \mu \mathrm{M}$ Val-tRF is shown. The scrambled version of the Val-tRF (scr) served as specificity control. In all cases, the background values measured in reactions without S30 extracts were subtracted from all experimental points. Error bars represent the mean and standard deviation of at least three independent experiments. (b) Cell growth of unstressed $H$. volcanii cultures and of cells grown under alkaline conditions $(\mathrm{pH}$ 8.5) is shown. Cell density was measured at $600 \mathrm{~nm}$ and the average values of two independent growth curves each and their standard deviations are given.

was indeed the cause of a P-site competition, we expected no reduction in the peptidyl transferase activity when ValtRF was added together with the A-site substrate puromycin to a ribosomal complex already prebound with $\mathrm{N}$-acetyl$\left[{ }^{3} \mathrm{H}\right]$ Phe-tRNA at the P-site. However, also under these experimental conditions a significant drop of peptide bond formation was observed (Figure 5(b)). Since the puromycin assay under these conditions has been shown before to be

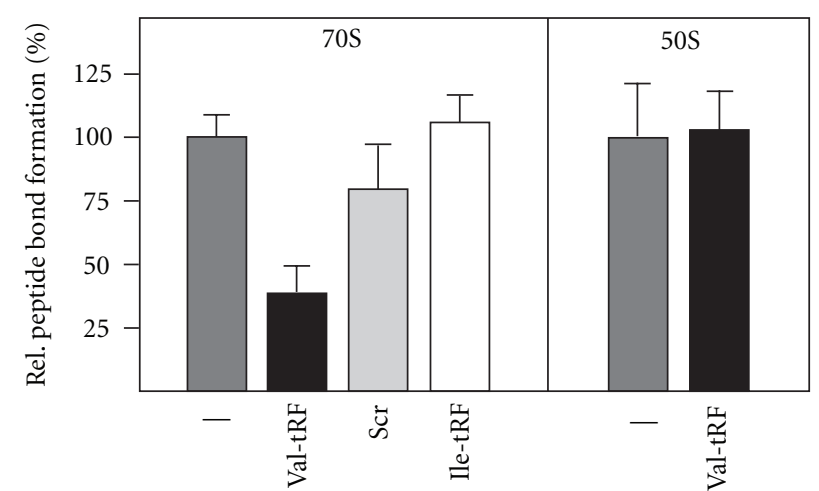

(a)

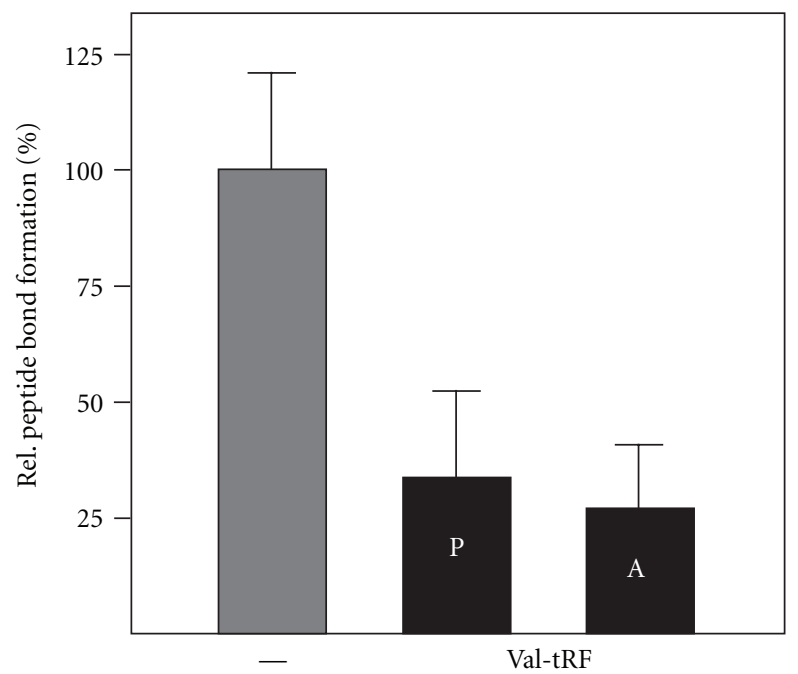

(b)

FIgure 5: Val-tRF inhibits peptide bond formation. (a) Peptidyl transferase reactions catalyzed by $H$. volcanii $70 S$ ribosomes (left panel) or 50S subunits (right panel) in the absence (-) or presence of $2.7 \mu \mathrm{M}$ Val-tRF (a 10-fold molar excess) were performed as described in Material and Methods. The scrambled version of the Val-tRF (scr) as well as Ile-tRF served as specificity controls. The relative amount of the reaction product $\mathrm{N}$-acetyl- $\left[{ }^{3} \mathrm{H}\right] \mathrm{Phe}-$ puromycin (in \%) is shown. The product formed in the absence of any tRF (-) was taken as $100 \%$. (b) Val-tRF inhibits peptide bond formation to the same extent regardless if it was added simultaneously with the P-site donor substrate $(\mathrm{P})$ or with the A-site acceptor substrate (A). In all cases, the background values measured in reactions without any ribosomal particles were subtracted from all experimental points. Error bars represent the mean and standard deviation of three to five independent experiments.

a single-turnover reaction [22], we conclude that Val-tRF does not interfere with peptide bond formation due to a competition with $\mathrm{N}$-acetyl- $\left[{ }^{3} \mathrm{H}\right] \mathrm{Phe}$-tRNA for the ribosomal P-site.

\section{Discussion}

Translation is essentially the last step where regulatory input can be given in the course of gene expression. Typically 
translation initiation, the rate limiting step of protein biosynthesis, is targeted by regulatory molecules which lead to either global or mRNA-specific effects on protein production [23]. Many regulatory proteins have been identified whose actions result in fine tuning protein synthesis rates thus enabling organisms and cells to adapt to changing environments or to fulfill tissue specific tasks. More recently also ncRNAs have been added to the list of regulatory entities that modulate translation with microRNAs and antisense RNAs being the most prominent classes in eukaryal and prokaryotic species, respectively [24]. Interestingly essentially all of these ncRNAs that control protein biosynthesis target the mRNAs rather than the ribosome itself, with 7SL RNA and tmRNA as notable exceptions (reviewed in $[25,26]$ ). This is unexpected given the central position the ribosome, a highly conserved multifunctional ribonucleoprotein (RNP) complex plays during gene expression. The fact that more than $50 \%$ of all natural antibiotic target the ribosome clearly shows that this highly conserved RNA enzyme is in principal an ideal target for manipulating the rate of gene expression [27]. Furthermore, it is assumed that the ribosome is an evolutionary relic from the RNA world where regulatory input likely was given by nonproteinous molecules, such as small ncRNAs.

In order to investigate whether or not small ncRNAs are still used by contemporary cells and organisms to regulate protein production, we have analyzed the RNA interactome of translating ribosomes. Our previous genomic screen in $S$. cerevisiae already indicated that such RNAs do exist [7]; thus we set out to look for this potentially novel class of ncRNAs in the halophilic archaeon Haloferax volcanii. Ribosomes were isolated from environmentally stressed cells and the small RNAs that copurified were analyzed by deep-sequencing analysis. Besides numerous other potential ncRNA regulators found to be associated with the ribosomes (our unpublished data), $26 \%$ of all obtained reads originated from tRNA loci. This by itself was not unexpected since tRNAs are abundant ncRNAs and well-known substrates of the ribosomes. More unforeseen, however, was the detection of 1.3 million reads originating from tRNA fragments (tRFs) (Table 1). 14 different tRNA species were found to be processed into tRFs almost exclusively from their $5^{\prime}$ ends (Figure 1). Stressdepandant processing of tRFs has been reported before in other model systems including yeast [7, 28], human cell lines [13, 15, 29], pumpkin [16], Aspergillus [14], $H$. volcanii [30], and others (see [8] and references therein). While the enzymes responsible for such tRNA processing in yeast (Rny1) [31] and mammalian cells (angiogenin) [29] have just very recently been identified, essentially nothing is known about tRF processing in archaea. In most of the cases the cellular target and the molecular function of tRFs remained unclear. In this paper, we show that tRFs from $H$. volcanii bind to the ribosome in vivo and in vitro (Figures 1-3). Importantly only tRFs derived from the $5^{\prime}$ part of genuine tRNA were capable for this interaction. With 1.1 million essentially identical sequence reads, the 26 nucleotide long tRF from the Val-tRNA (GAC) locus was by far the most abundant tRF found in our screen (Table 1). The northern blot signal for Val-tRF was faint when total cellular RNA was used (Figure 1(b)) but increased significantly when ribosome-associated RNA was employed, especially upon alkaline stress (Figure 1(c)). These findings suggest that tRNA processing is stress-independent, a finding that is in good agreement with a very recent study by Saikia et al. [32] and previous reports $[5,8,9,14,16]$ and shows that Val-tRF is preferentially bound to ribosomes upon shifting the cells to elevated $\mathrm{pH}$. Additional enrichment for functional ribosomal particles by polysome gradient analysis led to a further increase of the northern blot signal for ValtRF (Figure 3(b)). This polysome profiling approach and direct binding studies demonstrated the association of this tRF primarily with the small ribosomal subunit (Figure 3). Only under elevated $\mathrm{pH}$ conditions, Val-tRF signals were also found in the polysome fraction. Val-tRF was able to inhibit the translation of $H$. volcanii proteins in vitro (Figure 4(a)), most likely by interfering with peptide bond formation (Figure 5). Inhibition of amide bond synthesis was only seen in the context of 70S ribosomes, but not in 50 S subunits (Figure 5). These functional data support our findings that Val-tRF mainly binds to and acts on the small ribosomal subunit of $H$. volcanii. Since Val-tRF shifts into the polysomal fraction during $\mathrm{pH}$ stress (Figure 3(a)), it is possible that this interaction downregulates translational activity by interfering with efficient transpeptidation. This possible functional scenario can explain the slow growth phenotype of $H$. volcanii at elevated $\mathrm{pH}$ (Figure 4(b)), conditions where Val-tRF most strongly associates with ribosomes (Figure 1(c)).

The ever growing class of tRFs is not by far a homogenous group of RNA molecules. Markedly different processing patterns, sequence motifs, stress response behaviors, and (putative) mode of actions have been reported. In human cells, it was shown that a run of consecutive $G$ residues on the $5^{\prime}$-end of tRFs was crucial for inhibiting the translation initiation step [13]. However, most other tRF identified so far lack any $5^{\prime}$ homopolymeric stretches of nucleotides. Also the fate of the two potential tRNA halves $\left(5^{\prime}\right.$ or $\left.3^{\prime}\right)$ after processing seems to be diverse. In some cases both tRNA halves are stable in the cell and thus can be considered ncRNA candidates $[7,14,33,34]$ while in other cases $([7,13]$ and this study), primarily $5^{\prime}$ tRNA fragments were observed. Even within one species, the pattern of tRF biogenesis appears to vary evidently. A recent study by the Marchfelder group reported on the detection of 11 different tRFs in $H$. volcanii [30]. In that study total RNA of differently grown $H$. volcanii cells was used to generate the cDNA library for deep-sequencing analysis. Significantly, not a single tRF was identical when compared to our data despite the fact that the same archaeal strain was used and similar stress conditions were applied. Furthermore the tRF processing pattern in Heyer et al. was strikingly different [30]. All but one tRF derived from the $3^{\prime}$-trailer sequence of pretRNAs, and only one from the $5^{\prime}$-part of the tRNA. In our screen, however, nearly all tRFs were processed out from the $5^{\prime}$-ends of full length tRNA. One likely explanation for these apparent differences is that the ribosome selects specifically only tRFs originating from the $5^{\prime}$-ends of tRNAs. This strongly indicates that markedly different RNomes have 
been analyzed in these two studies, possibly reflecting the highly diverse ncRNA biology of tRNA-derived fragments. Additionally, recent evidence demonstrated [35] that the fraction of biologically functional ncRNA molecules can be increased when cDNA libraries were prepared from RNP particles (our approach) compared to naked total RNA [30].

In summary, we describe herein one of the first direct cellular target for tRFs, namely the ribosome. Furthermore we present evidence that the 26-residue-long Val-tRF is processed in a stress-dependent manner, primarily at elevated $\mathrm{pH}$ values and show that ribosome association of this RNA species downregulates protein biosynthesis. Thus we think that this RNA species fulfills all criteria to be referred to as regulatory ncRNA in $H$. volcanii.

\section{Acknowledgments}

Jörg Soppa and Anita Marchfelder are acknowledged for providing strains and reagents and for insightful discussions. The authors thank Kamilla Bakowska-Zywicka for initial help with the cDNA library preparation and Miriam Koch, Andreas Pircher, Nina Clementi, Matthias Erlacher, and Ronald Micura for critical comments on the paper. Our thanks are extended to Lavinia Furrer for her valuable help in optimizing polysome gradient conditions during her bachelor thesis. This work was supported by Grants from the Austrian Science Foundation FWF (Y315) and the Austrian Ministry of Science and Research (GenAU project consortium "non-coding RNAs" D-110420-012-012) to N.Polacek.

\section{References}

[1] A. Hüttenhofer, P. Schattner, and N. Polacek, "Non-coding RNAs: hope or hype?" Trends in Genetics, vol. 21, no. 5, pp. 289-297, 2005.

[2] P. P. Amaral, M. E. Dinger, T. R. Mercer, and J. S. Mattick, "The eukaryotic genome as an RNA machine," Science, vol. 319, no. 5871, pp. 1787-1789, 2008.

[3] C. Ender, A. Krek, M. R. Friedländer et al., "A human snoRNA with microRNA-like functions," Molecular Cell, vol. 32, no. 4, pp. 519-528, 2008.

[4] M. Brameier, A. Herwig, R. Reinhardt, L. Walter, and J. Gruber, "Human box C/D snoRNAs with miRNA like functions: expanding the range of regulatory RNAs," Nucleic Acids Research, vol. 39, no. 2, pp. 675-686, 2011.

[5] H. Kawaji, M. Nakamura, Y. Takahashi et al., "Hidden layers of human small RNAs," BMC Genomics, vol. 9, article 157, 2008.

[6] Z. Li, C. Ender, G. Meister, P. S. Moore, Y. Chang, and B. John, "Extensive terminal and asymmetric processing of small RNAs from rRNAs, snoRNAs, snRNAs, and tRNAs," Nucleic Acids Research, vol. 40, no. 14, pp. 6787-6799, 2012.

[7] M. Zywicki, K. Bakowska-Zywicka, and N. Polacek, "Revealing stable processing products from ribosome-associated small RNAs by deep-sequencing data analysis," Nucleic Acids Research, vol. 40, no. 9, pp. 4013-4024, 2012.

[8] D. M. Thompson and R. Parker, "Stressing out over tRNA cleavage," Cell, vol. 138, no. 2, pp. 215-219, 2009.

[9] Y. S. Lee, Y. Shibata, A. Malhotra, and A. Dutta, "A novel class of small RNAs: tRNA-derived RNA fragments (tRFs)," Genes and Development, vol. 23, no. 22, pp. 2639-2649, 2009.
[10] M. Bühler, N. Spies, D. P. Bartel, and D. Moazed, "TRAMPmediated RNA surveillance prevents spurious entry of RNAs into the Schizosaccharomyces pombe siRNA pathway," Nature Structural and Molecular Biology, vol. 15, no. 10, pp. 10151023, 2008.

[11] C. Cole, A. Sobala, C. Lu et al., "Filtering of deep sequencing data reveals the existence of abundant Dicer-dependent small RNAs derived from tRNAs," RNA, vol. 15, no. 12, pp. $2147-$ 2160, 2009.

[12] D. Haussecker, Y. Huang, A. Lau, P. Parameswaran, A. Z. Fire, and M. A. Kay, "Human tRNA-derived small RNAs in the global regulation of RNA silencing," RNA, vol. 16, no. 4, pp. 673-695, 2010.

[13] P. Ivanov, M. M. Emara, J. Villen, S. P. Gygi, and P. Anderson, "Angiogenin-induced tRNA fragments inhibit translation initiation," Molecular Cell, vol. 43, no. 4, pp. 613-623, 2011.

[14] C. Jöchl, M. Rederstorff, J. Hertel et al., "Small ncRNA transcriptome analysis from Aspergillus fumigatus suggests a novel mechanism for regulation of protein synthesis," Nucleic Acids Research, vol. 36, no. 8, pp. 2677-2689, 2008.

[15] S. Yamasaki, P. Ivanov, G. F. Hu, and P. Anderson, "Angiogenin cleaves tRNA and promotes stress-induced translational repression," Journal of Cell Biology, vol. 185, no. 1, pp. 35-42, 2009.

[16] S. Zhang, L. Sun, and F. Kragler, "The phloem-delivered RNA pool contains small noncoding RNAs and interferes with translation," Plant Physiology, vol. 150, no. 1, pp. 378-387, 2009.

[17] J. Straub, M. Brenneis, A. Jellen-Ritter, R. Heyer, J. Soppa, and A. Marchfelder, "Small RNAs in haloarchaea: identification, differential expression and biological function," RNA Biology, vol. 6, no. 3, pp. 281-292, 2009.

[18] P. Khaitovich, T. Tenson, P. Kloss, and A. S. Mankin, "Reconstitution of functionally active Thermus aquaticus large ribosomal subunits with in vitro-transcribed rRNA," Biochemistry, vol. 38, no. 6, pp. 1780-1788, 1999.

[19] G. Ring, P. Londei, and J. Eichler, "Protein biogenesis in Archaea: addressing translation initiation using an in vitro protein synthesis system for Haloferax volcanii," FEMS Microbiology Letters, vol. 270, no. 1, pp. 34-41, 2007.

[20] R. E. Monro and K. A. Marcker, "Ribosome-catalysed reaction of puromycin with a formylmethionine-containing oligonucleotide," Journal of Molecular Biology, vol. 25, no. 2, pp. 347350, 1967.

[21] N. Polacek, S. Swaney, D. Shinabarger, and A. S. Mankin, "SPARK - a novel method to monitor ribosomal peptidyl transferase activity," Biochemistry, vol. 41, no. 39, pp. 1160211610, 2002.

[22] M. D. Erlacher, K. Lang, N. Shankaran et al., "Chemical engineering of the peptidyl transferase center reveals an important role of the 2'-hydroxyl group of A2451," Nucleic Acids Research, vol. 33, no. 5, pp. 1618-1627, 2005.

[23] F. Gebauer and M. W. Hentze, "Molecular mechanisms of translational control," Nature Reviews Molecular Cell Biology, vol. 5, no. 10, pp. 827-835, 2004.

[24] J. S. Mattick and I. V. Makunin, "Non-coding RNA," Human molecular genetics, vol. 15, supplement 1, pp. R17-R29, 2006.

[25] C. Zwieb and S. Bhuiyan, "Archaea signal recognition particle shows the way," Archaea, vol. 2010, Article ID 485051, 11 pages, 2010.

[26] B. D. Janssen and C. S. Hayes, "The tmRNA ribosome-rescue system," Advances in Protein Chemistry and Structural Biology, vol. 86, pp. 151-191, 2012. 
[27] D. N. Wilson, "The A-Z of bacterial translation inhibitors," Critical Reviews in Biochemistry and Molecular Biology, vol. 44, no. 6, pp. 393-433, 2009.

[28] D. M. Thompson, C. Lu, P. J. Green, and R. Parker, "tRNA cleavage is a conserved response to oxidative stress in eukaryotes," RNA, vol. 14, no. 10, pp. 2095-2103, 2008.

[29] H. Fu, J. Feng, Q. Liu et al., "Stress induces tRNA cleavage by angiogenin in mammalian cells," FEBS Letters, vol. 583, no. 2, pp. 437-442, 2009.

[30] R. Heyer, M. Dorr, A. Jellen-Ritter et al., "High throughput sequencing reveals a plethora of small RNAs including tRNA derived fragments in Haloferax volcanii," RNA Biology, vol. 9, no. 7, pp. 1011-1018, 2012.

[31] D. M. Thompson and R. Parker, “The RNase Rnylp cleaves tRNAs and promotes cell death during oxidative stress in Saccharomyces cerevisiae," Journal of Cell Biology, vol. 185, no. 1, pp. 43-50, 2009.

[32] M. Saikia, D. Krokowski, B. J. Guan et al., "Genomewide identification and quantitative analysis of cleaved tRNA fragments induced by cellular stress," The Journal of Biological Chemistry, vol. 287, no. 51, pp. 42708-42725, 2012.

[33] M. R. Garcia-Silva, M. Frugier, J. P. Tosar et al., "A population of tRNA-derived small RNAs is actively produced in Trypanosoma cruzi and recruited to specific cytoplasmic granules," Molecular and Biochemical Parasitology, vol. 171, no. 2, pp. 64-73, 2010.

[34] H. J. Haiser, F. V. Karginov, G. J. Hannon, and M. A. Elliot, "Developmentally regulated cleavage of tRNAs in the bacterium Streptomyces coelicolor," Nucleic Acids Research, vol. 36, no. 3, pp. 732-741, 2008.

[35] M. Rederstorff and A. Hüttenhofer, "CDNA library generation from ribonucleoprotein particles," Nature Protocols, vol. 6, no. 2, pp. 166-174, 2011. 

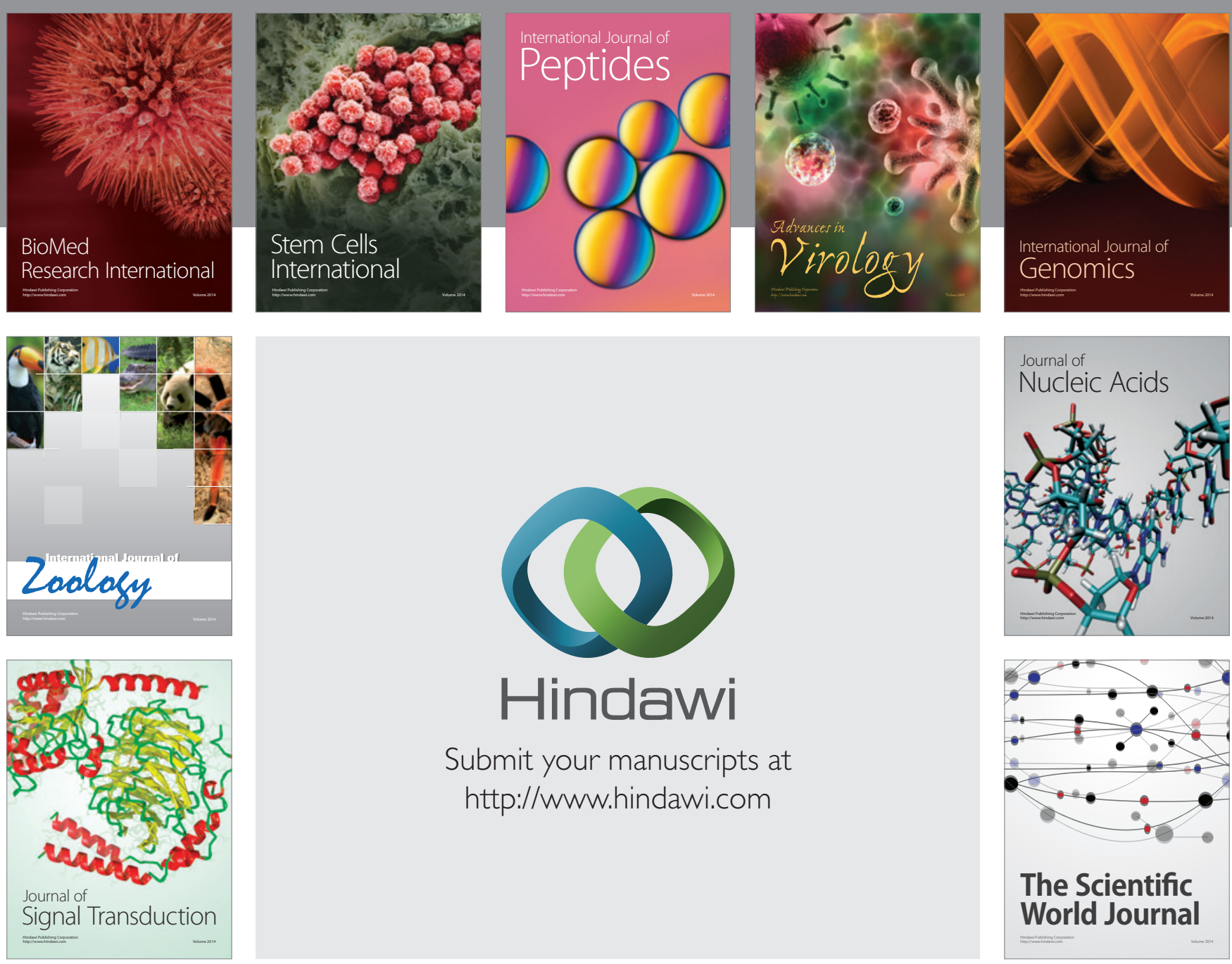

Submit your manuscripts at

http://www.hindawi.com
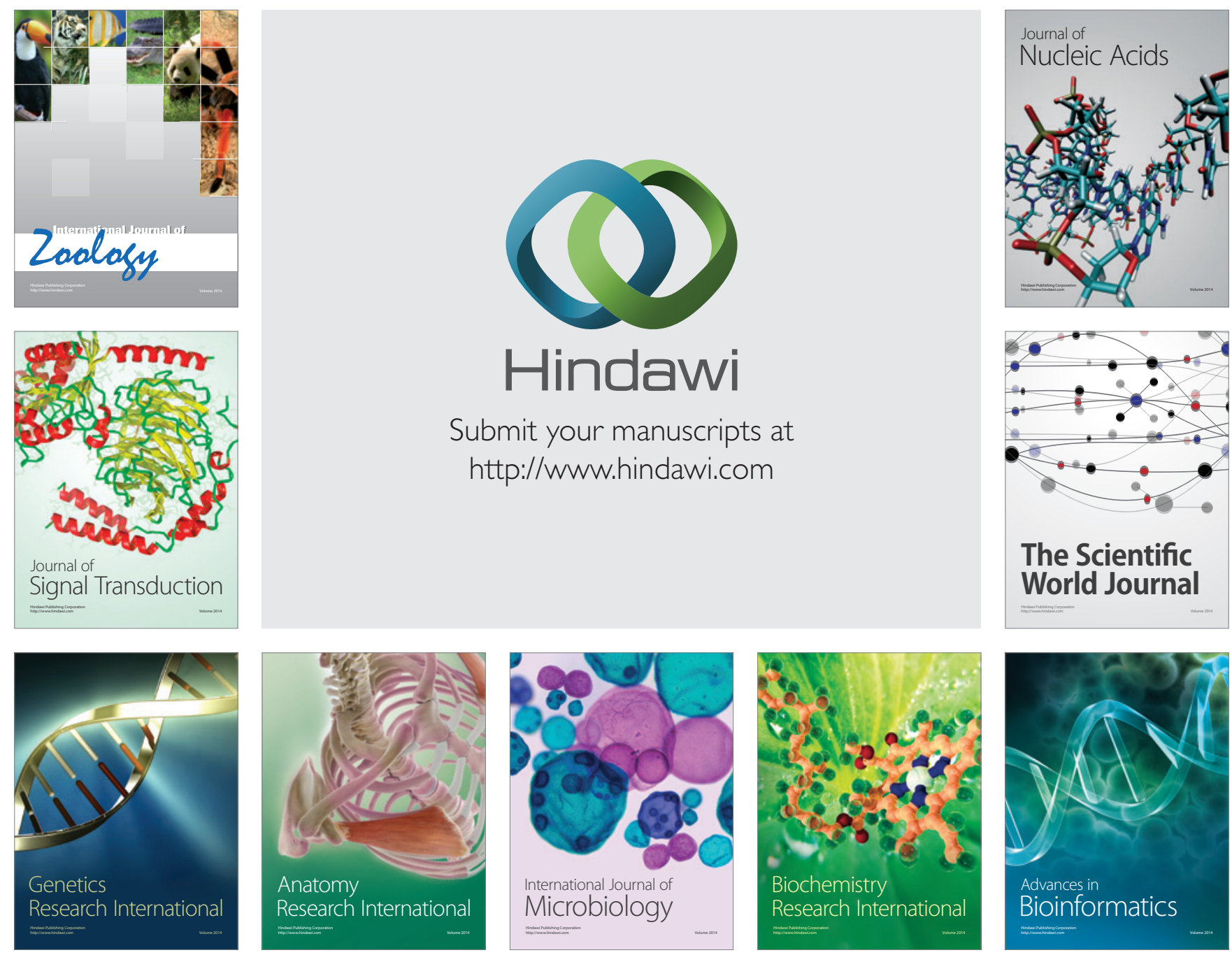

The Scientific World Journal
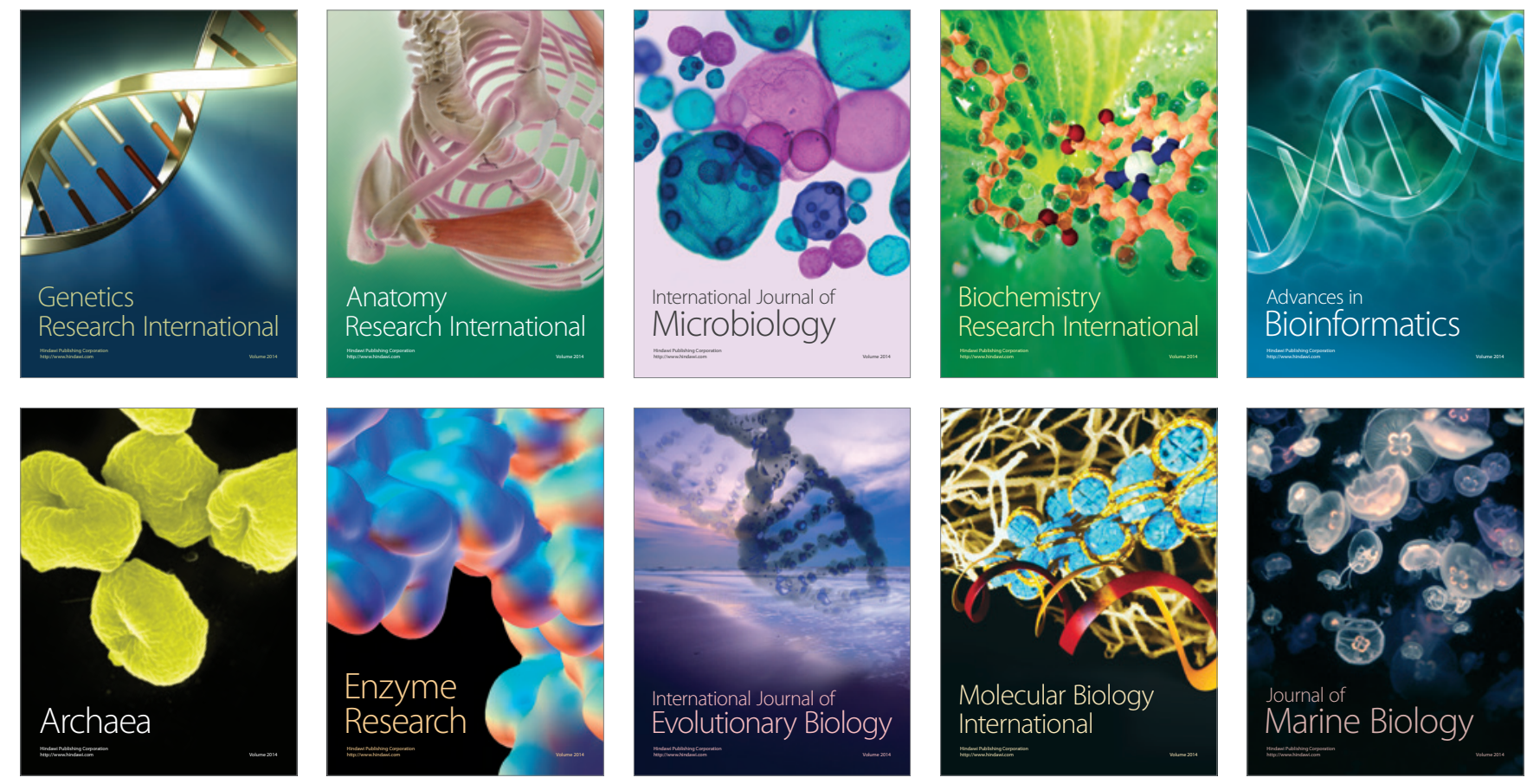